\title{
Research on the Coordinated Effects of Industrialization and Urbanization Driven by Multi-Stage Innovation
}

\author{
Yulei Xie* \\ School of Economics and Management, Beijing Jiao Tong University, Beijing, PR China \\ *Corresponding author. Email:505136118@qq.com
}

\begin{abstract}
Following the progress of industrialization and urbanization in the report of the 18th National Congress and the 2018 government work report, General Secretary Xi Jinping clearly stated the important development direction of the simultaneous development of industrialization and urbanization in the report of the 19th National Congress. In this paper, the coupling coordination degree model is used to study the coupling degree of industrialization and urbanization driven by innovation input in 30 provinces in mainland China from 2000 to 2016. In the end, it is believed that innovation investment is conducive to the coordinated development of industrialization and urbanization, and increasing investment in innovation is conducive to improving the coordination level of industrialization and urbanization. It is recommended to increase the expenditure of basic R\&D personnel and R\&D expenditures, strengthen the cultivation of innovative talents, improve the ability of independent innovation, and lay a solid foundation for promoting the coordinated investment of industrialization and urbanization.
\end{abstract}

Keywords: Innovation input, Industrialization, Urbanization, Coupling coordination.

\section{INTRODUCTION}

Industrialization and urbanization are the necessary stages for the economic and social development of a country or region and the only way for economic modernization. Scholars at home and abroad have carried out a lot of fruitful research on the relationship between innovation investment, industrialization and urbanization, which is the important research basis of this article. However, few scholars systematically combed the coordination mechanism of innovation input driving industrialization and urbanization. At the same time, there is no empirical analysis of innovation input driving the coordinated development of industrialization and urbanization. Therefore, based on an in-depth analysis of the mechanism of innovation input driving the coordination of industrialization and urbanization, this paper collects 30 province-level administrative regions in mainland China (excluding Hong Kong, Macao, Taiwan and Tibet) from 2000 to 2016. Relevant data are empirically analyzed using panel metering model and coupling coordination model to analyze the impact of innovation input on the coordinated development of China's industrialization and urbanization.

\section{INTERNAL MECHANISM OF MODEL}

Innovation input refers to all the necessary human, material and financial resources invested by an enterprise in order to ensure the smooth progress of innovation activities when carrying out innovative research and development. The innovation input system is an open system with high complexity, diversity, and dynamics. There are also complex relationships among the many elements that make up the composite system. Considering that innovation is a dynamic time process and exhibits different characteristics at different stages, this article divides the innovation input process into four stages: initial innovation input, intermediate innovation input, initial outcome input, and final outcome input. Figure 1 shows the four stages of innovation investment and their impact on the coordinated development of industrialization and urbanization: 


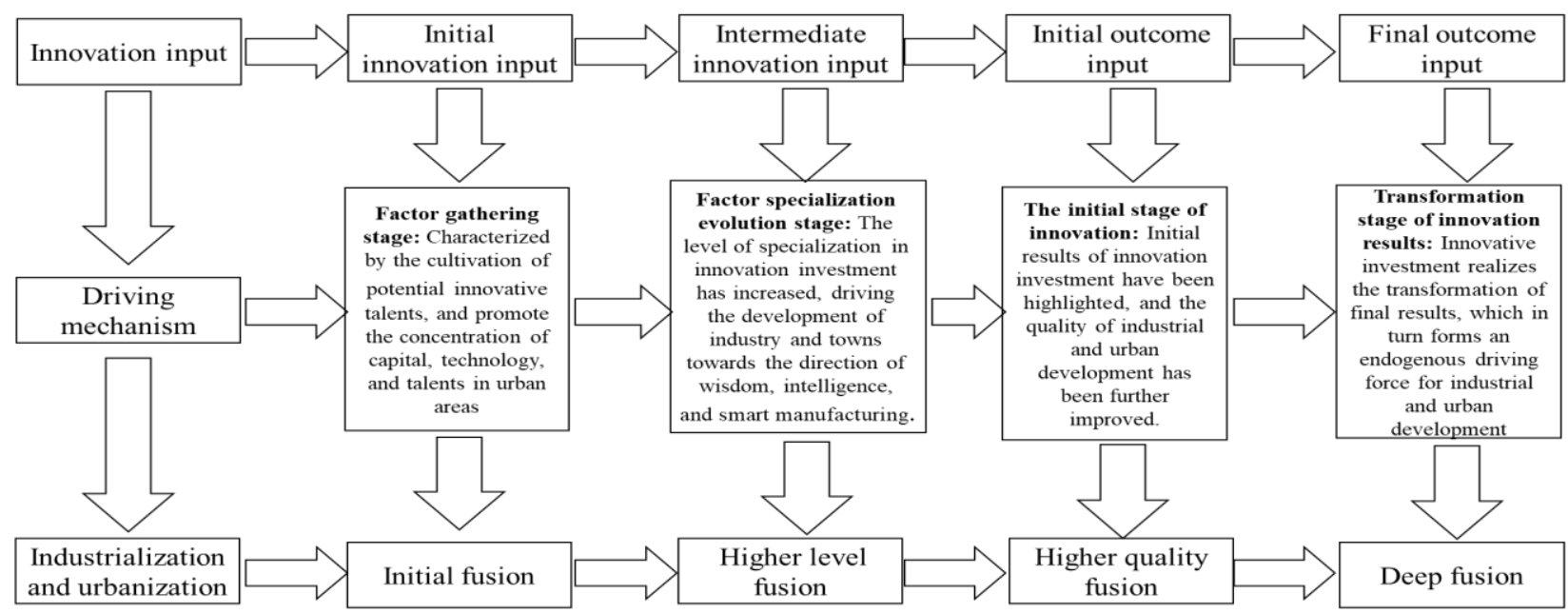

Figure 1 Principles of Coordinated Development of Industrialization and Urbanization Driven by Innovation Input

Table 1. Panel fixed effect model regression results

\begin{tabular}{|c|c|c|c|c|c|c|c|}
\hline Industrial system & Coefficient & t-Statistic & Prob. & Urbanization system & Coefficient & t-Statistic & Prob. \\
\hline $\begin{array}{c}\text { College students } \\
\text { over the years }\end{array}$ & 6.784 & 1.71 & 0.089 & $\begin{array}{c}\text { College students over the } \\
\text { years }\end{array}$ & 56.211 & 12.01 & 0.000 \\
\hline $\begin{array}{c}\text { Expenditure on } \\
\text { scientific research }\end{array}$ & -2.763 & -1.37 & 0.171 & $\begin{array}{c}\text { Expenditure on scientific } \\
\text { research }\end{array}$ & 3.634 & 1.53 & 0.126 \\
\hline $\begin{array}{c}\text { Proportion of } \\
\text { scientific research } \\
\text { personnel }\end{array}$ & 0.103 & 3.86 & 0.000 & $\begin{array}{c}\text { Proportion of scientific } \\
\text { research personnel }\end{array}$ & -0.035 & -1.10 & 0.273 \\
\hline Patent grants & -0.003 & -1.60 & 0.110 & Patent grants & 0.001 & 0.41 & 0.679 \\
\hline $\begin{array}{c}\text { Technology market } \\
\text { transaction }\end{array}$ & 0.037 & 0.14 & 0.887 & $\begin{array}{c}\text { Technology market } \\
\text { transaction }\end{array}$ & 0.659 & 2.12 & 0.034 \\
\hline $\begin{array}{c}\text { Foreign direct } \\
\text { investment }\end{array}$ & 0.386 & 0.67 & 0.505 & Foreign direct investment & -0.163 & -0.24 & 0.811 \\
\hline $\begin{array}{c}\text { Government } \\
\text { spending }\end{array}$ & -0.147 & -3.86 & 0.000 & Government spending & 0.040 & 0.89 & 0.374 \\
\hline Total social retail & 0.300 & 8.17 & 0.000 & Total social retail & 0.064 & 1.48 & 0.138 \\
\hline $\begin{array}{c}\text { Social fixed } \\
\text { investment }\end{array}$ & -0.598 & -7.24 & 0.000 & Social fixed investment & -0.285 & -2.93 & 0.004 \\
\hline
\end{tabular}

\section{VARIABLES AND DATA SOURCES}

\subsection{Establishment of Indicator System}

According to the connotation and characteristics of innovation input, industrialization and urbanization systems, and in accordance with the principles of scientificity, systematicness, hierarchy, dynamics, and operability, considering the representativeness of indicators and the availability of data, combined with the innovation and development of China The actual situation, the establishment of industrialization, urbanization, innovation investment index system. Considering the complexity of the connotation of the industrialization and urbanization system, a single evaluation index cannot fully reflect the characteristics of industrialization and urbanization, so this article measures it by constructing a corresponding comprehensive index system.

\subsection{Coupling Degree Model}

Coupling degree is an important index reflecting the degree of coupling between systems. It can be used to judge the strength of the interaction between innovation input and industrialization and innovation input and urbanization. Drawing on the concept of capacity coupling and the model of capacity coupling coefficient in physics, build a coupling degree model of innovation investment and industrialization and urbanization:

$C=2\left[\frac{U_{1} \times U_{2}}{\left(U_{1}+U_{2}\right)^{2}}\right]^{1 / 2}$

\subsection{Coupling Coordination Model}

It is necessary to further improve the model and build a coupling coordination degree model.

$D=\sqrt{C \times T}$ 


$$
T=\alpha U_{1}+\beta U_{2}
$$

In the formula: $\mathrm{D}$ is the degree of coupling and coordination, $\mathrm{T}$ is the comprehensive development index of innovation input and industrialization and urbanization, which reflects the overall level of efficiency of the three. Considering that both are equally important in the process of socio-economic development, this article takes $\alpha=\beta=0.5$.

\section{EMPIRICAL ANALYSIS}

\subsection{Decomposition of Innovation Input Factors Based on Panel Measurement Model}

It can be seen that human resources have a significant impact on the industrialization and urbanization systems. Each 1\% increase in the number of college students in human resources levels over the years will be accompanied by an increase in $6.784 \%$ industrialization and $56.211 \%$ urbanization; the more $R \& D$ research expenditure, The more expenditure can be used to purchase basic research and development equipment and scientific research equipment. As the level of infrastructure gradually increases, the conditions of urbanization and infrastructure construction are improved, and the living standards and quality of urbanization are significantly improved. Development plays an important role. However, at this stage, China's innovation investment system is still immature, and traditional industrialization and urbanization have not focused on the positive effects of scientific research expenditures on industrialization and urbanization. The impact of R\&D researchers on industrialization and urbanization is similar. For every $1 \%$ increase in $\mathrm{R} \& \mathrm{D}$ researchers, the industrialization level increases by $0.103 \%$, and the degree of urbanization is not significant. $R \& D$ researchers as a source of innovation can help improve the technological content of R\&D products. Bring rich innovation input and output, improve industrialized production conditions, speed up the transformation of industrial structure, and promote the level of industrialization. In addition, the number of patent grants does not have a significant impact on the industrialization and urbanization system. At this stage, China's weak copyright consciousness, coupled with the high risk of investment in innovation activities, therefore has not played a significant role in promoting industrialization and urbanization; and technology market transactions have no significant effect on urbanization. There is a significant impact on the industrialization system. As the technology market transaction volume increased by $1 \%$, the level of urbanization increased by $0.659 \%$.

\subsection{Measurement of the Coordinated Development of Industrialization and Urbanization Driven by Innovation Input}

The level of coordination of industrialization and urbanization driven by innovation investment is on the rise. In general, the level of coupling and coordination between industrialization and urbanization driven by innovation input in China's provinces has been increasing year by year since 2000 . The average value of the degree of coupling and coordination rose from 0.393 in 2000 to 0.519 in 2008 , and then to 0.561 in 2016. In 2000, there were 7 provincial-level administrative regions in Inner Mongolia, Qinghai, Ningxia, Yunnan, Guizhou, Guangxi, and Hainan at the stage of $0.00-0.35$. Only four regions of Qinghai, Yunnan, Guizhou, and Guangxi belonged to this type by 2008 This type of region did not exist in 2016. According to Figure 2, it can also be seen that the main distribution type in 2000 was the distribution type of $0.35-0.45$, and the coordination type in 2008 and 2016 was $0.45-0.55$. It can be seen that the contribution of innovation investment to the coordinated and coordinated development of China's industrialization and urbanization has become increasingly prominent. By increasing innovation investment, it can effectively drive the coordinated development of the two. On the other hand, innovation investment has contributed to industrialization and urbanization. The driving role of coupled development has evolved from the high-speed development from 2000-2008 to the stable development stage from 2008-2016. The former reason is that innovation investment not only promotes the concentration of population in urban areas, but also promotes the concentration of capital, technology, and industries in urban areas, thereby forming a situation of simultaneous concentration of industry and population, thereby promoting the level of coordination of industrialization and urbanization development. Continuous improving. The reason for the latter is that China's current level of industrialization and urbanization has made great progress, promoting the transformation of the industrial structure from manufacturing as the mainstay to high-tech industrial services and service industries as the mainstay, and for the interactive development of industrialization and urbanization Powered. The development of industrialization and urbanization is also undergoing a transition from high-speed development to high-quality development. While steadily increasing the level of industrialization and urbanization development, more emphasis is placed on quality improvement. Industrialization and urbanization are changes in the industrial structure and population structure in economic development.

The coordination of industrialization and urbanization driven by innovation input shows the characteristics of convergence. Judging from the 
division criteria for the coupling of innovation input to drive industrialization and urbanization, China's inter-provincial innovation input drives the degree of coupling and coordination of industrialization and urbanization across five levels, ranging from 0.32 to 0.96, of which Beijing's coupling coordination degree is the highest. And the lowest values are located in Qinghai and Guizhou provinces, respectively. There is an increasing trend between the highest and lowest values, rising from 0.427 in 2000 to 0.484 in 2008 and 0.501 in 2016 . From the perspective of coupling types, a total of 5 types of coupling coordination are involved, and only Beijing has always maintained the highest level of coordination. There are not many highly coordinated provinces, but the number has increased. In 2000, only Shanghai achieved a high level of coordination. Most provinces are in a state of basic coordination. The number of provinces that are basically coordinated is 21 , accounting for about $70 \%$ of the total number of coordination types. There are also Guangxi, Hainan, Guizhou, Yunnan, and Qinghai provinces. Faced with extremely uncoordinated innovation inputs to drive industrialization and urbanization. In 2008, the number of highly coordinated provinces increased to three provinces of Liaoning, Hubei, and Shaanxi. All provinces have reached the level of basic coordination and above, and the number of moderately coordinated provinces has increased from 2 in 2000 to 20 in 2008. In the 20 provinces of the year, the extremely coordinated provinces In addition to Beijing in 2000, Shanghai and Tianjin have also entered into extremely coordinated development provinces. As of 2016, in addition to Liaoning and Hubei provinces, 6 provinces of Jilin, Jiangsu, Jiangxi, Hainan, Chongqing, and Sichuan have developed to a highly coordinated level, accounting for $26 \%$ of the total number of coordination types, of which the number of moderately coordinated provinces has been reduced to 18 . The number of highly coordinated provinces increased to four, and innovation input drove the coordinated development of industrialization and urbanization significantly.

\section{CONCLUSIONS}

The research in this paper draws the following conclusions:

(1) Driven by innovation input, the level of industrialization and urbanization as a whole is increasing year by year, and the overall score growth rate has also increased.

(2) China 's inter-provincial innovation input drives the level of coordination between industrialization and urbanization as a whole. In terms of time, the average level of coupling coordination has shown an upward trend, and the coupling coordination has been optimized, but only a few regions have achieved an upward jump in the type of coupling and coordination. The type of coupling coordination is mainly moderate coordination, the number of highly and extremely coordinated provinces is not large, and most of them are distributed in the eastern economically developed regions, showing that there is a high correlation between economic development and the degree of coupling coordination.

\section{REFERENCES}

[1] Kojima R. Introduction: Population Migration and Urbanization in Development Countries [J]. Developing Economies, 1996, 34(4): 349-369.

[2] Lu G Y, Fu X Y, Zhu S E. Research on Relevance between Industrial Cluster and Urbanization Based on Canonical Analysis[J]. China Soft Science, 2011, (12): 101-109.

[3] Li G P. The Analysis and Evaluation of the Compatible Relationship between Industrialization and Urbanization in China[J]. Areal Research and Development, 2008, 27(5): 6-11.

[4] Zhou Y X. The Speed of Urbanization: the faster, not the better $[\mathrm{J}]$. Scientific Decision-Making, 2005, (8): 30-33.

[5] Hong M Y. A Study on the Coordination Development of Urbanization and Industrialization[J]. Journal of Guizhou University (Social Sciences), 2011, 29(6):64-71.

[6] Lv L Z. The Status and Function of Technology Innovation in the New Pattern of Industrialization[J]. China Soft Science, 2003, (12): 152-155.

[7] Qian J. Innovation Drive: the Mode Transformation of China's Industrialization-An Analysis from the Perspective of Enterprise and Education [J]. Journal of Management, 2017, 30(3): 1-9.

[8] Li J J, Meng M. Based on the Innovation Drive: America's Reindustrialization and China's Manufacturing Industry Transformation[J]. Science \& Technology Progress and Policy, 2016, 33(5): 51-55.

[9] Zhang J W, Cai Y F. General Trends of Urbanization and Rational Distribution of Urban Population in China[J]. Chinese Journal of Population Science, 2012, (6): 44-57. 